\title{
Overcoming the urge to splurge: Influencing eating behavior by manipulating inhibitory control
}

Citation for published version (APA):

Houben, K. (2011). Overcoming the urge to splurge: Influencing eating behavior by manipulating inhibitory control. Journal of Behavior Therapy and Experimental Psychiatry, 42(3), 384-388.

https://doi.org/10.1016/j.jbtep.2011.02.008

Document status and date:

Published: 01/09/2011

DOI:

10.1016/j.jbtep.2011.02.008

Document Version:

Publisher's PDF, also known as Version of record

Document license:

Taverne

Please check the document version of this publication:

- A submitted manuscript is the version of the article upon submission and before peer-review. There can be important differences between the submitted version and the official published version of record.

People interested in the research are advised to contact the author for the final version of the publication, or visit the DOI to the publisher's website.

- The final author version and the galley proof are versions of the publication after peer review.

- The final published version features the final layout of the paper including the volume, issue and page numbers.

Link to publication

\footnotetext{
General rights rights.

- You may freely distribute the URL identifying the publication in the public portal. please follow below link for the End User Agreement:

www.umlib.nl/taverne-license

Take down policy

If you believe that this document breaches copyright please contact us at:

repository@maastrichtuniversity.nl

providing details and we will investigate your claim.
}

Copyright and moral rights for the publications made accessible in the public portal are retained by the authors and/or other copyright owners and it is a condition of accessing publications that users recognise and abide by the legal requirements associated with these

- Users may download and print one copy of any publication from the public portal for the purpose of private study or research.

- You may not further distribute the material or use it for any profit-making activity or commercial gain

If the publication is distributed under the terms of Article $25 \mathrm{fa}$ of the Dutch Copyright Act, indicated by the "Taverne" license above, 


\title{
Overcoming the urge to splurge: Influencing eating behavior by manipulating inhibitory control
}

\author{
Katrijn Houben* \\ Clinical Psychological Science, Maastricht University, PO Box 616, 6200 MD Maastricht, The Netherlands
}

\section{A R T I C L E I N F O}

\section{Article history:}

Received 22 November 2010

Received in revised form

25 January 2011

Accepted 17 February 2011

\section{Keywords:}

Food

Overeating

Impulsivity

Inhibition

Stop signal task

\begin{abstract}
A B S T R A C T
Background and objectives: When inhibitory control is lacking, people are more prone to indulge in high calorie food. This research examined whether increasing or decreasing inhibitory control influences food intake in opposite directions.

Methods: In this study, baseline inhibitory control ability was measured with the Stop Signal Task. Next, participants performed a modified Stop Signal Task with three within-subjects conditions: One type of high calorie food was always paired with a stop signal (inhibition manipulation), while another type of high calorie food was never presented with a stop signal (impulsivity manipulation). In the control condition, high calorie food was presented with a stop signal on half the trials. Following the manipulation, intake of the three food products that were used in the manipulation was measured during a taste test.

Results: Participants with low inhibitory control abilities consumed more of the control food compared to participants with high inhibitory control abilities. However, the inhibition manipulation decreased food consumption in participants with low levels of inhibitory control to the same level of food intake as that of participants with high levels of inhibitory control. Conversely, the impulsivity manipulation increased food intake in participants with high levels of inhibitory control to the level of consumption of participants with low levels of inhibitory control.

Conclusions: These findings demonstrate the causal role of inhibition in eating behavior and suggest that strengthening inhibitory control can help people regain control over the consumption of high calorie food.
\end{abstract}

(C) 2011 Elsevier Ltd. All rights reserved.

\section{Introduction}

In Western societies, where palatable, high calorie food is abundantly available, the prevalence of overweight and obesity is constantly increasing (Flegal, 2005; Wang \& Beydoun, 2007). However, not everyone becomes overweight in this obesifying society: Some people can better resist the temptations of highcaloric food, and maintain a healthy weight than others. What distinguishes people with a normal weight from people with overweight? Although multiple factors contribute to overweight and obesity, one factor that seems especially important is inhibitory control: An executive function that is needed to overrule or inhibit impulsive reactions so that behavior can be regulated in line with one's long-term goals and standards (Logan \& Cowan, 1984; Miyake, Friedman, Emerson, Witzki, \& Howerter, 2000).

\footnotetext{
* Tel.: +31 433881953.

E-mail address: K.Houben@maastrichtuniversity.nl.
}

According to contemporary dual-process models (e.g., Strack \& Deutsch, 2004), inhibitory control plays a critical role whenever conflicts arise between the impulse to give into temptation and personal dieting standards or health concerns.

Specifically, dual-process models state that behavior is determined by two qualitatively different types of processes. One the one hand, a fast-acting, high-capacity, associative "impulsive system" appraises stimuli automatically in terms of affective and motivational significance and predisposes individuals to either approach or avoid a certain stimulus (e.g., Strack \& Deutsch, 2004). Such automatic, affective reactions toward tasty food trigger the motivational drive to indulge in these types of food (Appelhans, 2009; Dawe \& Loxton, 2004; Strack \& Deutsch, 2004). On the other hand, behavior is also guided by long-term goals and personal standards that reside in a slow-acting, low-capacity, controlled "reflective system" (e.g., Strack \& Deutsch, 2004). Whenever conflicts arise between the motivational drive to indulge in high calorie food and personal goals such as dieting standards, the motivational drive needs to be overruled by higher-order inhibitory 
control processes, so that behavior is in line with more deliberate long-term goals (Strack \& Deutsch, 2004). Consequently, when inhibitory control is somehow impaired, the motivational drive will be more dominant in guiding eating behavior, leaving one unable to resist the temptations of high calorie, palatable food.

Consistent with this theoretical perspective, empirical evidence shows a vital role for inhibitory control in overeating and overweight: People with a weaker ability to inhibit impulsive responses are more vulnerable to the temptations of tasty, high calorie food and eat more high calorie food (Guerrieri et al., 2007), are more often unsuccessful dieters (Jansen et al., 2009), and are more often overweight or obese (Guerrieri, Nederkoorn, \& Jansen, 2008; Nederkoorn, Braet, Van Eijs, Tanghe, \& Jansen, 2006; Nederkoorn, Guerrieri, Havermans, Roefs, \& Jansen, 2009; Nederkoorn, Jansen, Mulkens, \& Jansen, 2007) than people with effective inhibitory control. Further, automatic affective responses more strongly determine consumption of high calorie food (Friese, Hofmann, \& Wänke, 2008; Hofmann \& Friese, 2008; Hofmann, Friese, \& Roefs, 2009; Hofmann, Rauch, \& Gawronski, 2007) as well as weight gain (Nederkoorn, Houben, Hofmann, Roefs, \& Jansen, 2010) when inhibitory control is weak.

Thus, the available evidence seems to suggest a causal role for inhibitory control in overeating and obesity. The clinical implication is that interventions aimed at reducing overeating and overweight might benefit from procedures that aim to strengthen inhibitory control abilities. If inhibitory control can somehow be enhanced, automatic impulses could be regulated more easily and control over food intake could be increased. While most of the studies examining the role of inhibitory control in obesity and overeating have been correlational in nature, there is also evidence supporting such a causal influence of inhibitory control on eating behavior: Guerrieri, Nederkoorn, Schrooten, Martijn, and Jansen (2009) demonstrated decreased food intake following a manipulation that primed inhibitory control compared to a manipulation that primed impulsive behavior. However, in this study, there was no control condition, which makes it impossible to determine whether both the impulsivity and the inhibition manipulation effectively influenced food intake relative to baseline. Moreover, Guerrieri et al. (2009) used a priming manipulation to induce a temporary state of impulsivity or inhibition. While such a priming paradigm is interesting to show causal relationships, it is highly unlikely that priming inhibition will induce long-term effects on both inhibitory abilities and eating behavior.

The current study takes this research a step further by examining whether increasing or decreasing inhibitory control respectively decreases or increases food intake relative to a control condition. Moreover, the present study tested a behavioral training of inhibition that consistently paired certain stimuli with a stopping response. A similar manipulation has been previously shown to effectively strengthen the ability to inhibit responses to those stimuli that were paired with a stopping response (Verbruggen \& Logan, 2008). Since weak inhibitory control abilities can be considered a risk factor for overeating and obesity, such inhibition training may prove to be especially effective for people with low inhibitory control abilities. This issue was also investigated in the present research. Specifically, an adapted version of the Stop Signal Task (SST; Logan, Schachar, \& Tannock, 1997), a behavioral task that is typically used to measure inhibitory control ability, was used to train participants to react impulsively toward a certain food product (i.e., acting fast toward palatable food stimuli) and to inhibit responding to another food product (i.e., stopping responses toward palatable food stimuli). A control food product was included toward which participants reacted on half the trials and inhibited their responses on the other half of the trials. In a subsequent taste test, consumption of these three food products was measured. By including a control condition, it was possible to unambiguously test
(1) whether the impulsivity manipulation increased food intake, and (2) whether the inhibition manipulation decreased food intake. Further, baseline inhibitory control was measured using the original SST, to examine (3) if the manipulation had differential effects on food intake depending on the initial level of inhibitory control.

\section{Method}

\subsection{Participants}

Before inclusion in the study, participants were screened on attitudes toward the three types of food that were used in the manipulation: Attitudes toward crisps, nuts, and M\&M's were measured with 5 semantic differentials that were scored on a $100 \mathrm{~mm}$ visual analog scale (unpleasant-pleasant, bad-good, foolish-wise, awful-nice, unpalatable-palatable). Only participants who liked crisps, nuts, and M\&M's to a similar extent (i.e., mean attitude scores toward the three the types of food did not differ more than 25 points) were included in the study. In total, thirty-two female undergraduate students were selected for this study. Three participants were aware of the goal of the study and were therefore subsequently removed from the sample. The final sample consisted of twenty-nine participants (age: $M=21.15, S D=1.81$; Attitudes: Crisps: $M=62.11, S D=9.49$; Nuts: $M=61.87, S D=13.86$; M\&M's: $M=64.40, S D=14.30)$. Participants had a mean Body Mass Index $\left(\mathrm{kg} / \mathrm{m}^{2}\right.$; BMI) of $23.12(\mathrm{SD}=4.27$; range $18.83-40.40)$, while $17.2 \%$ of the participants had a BMI higher than or equal to 25 .

\subsection{Materials and measures}

\subsubsection{Stop signal task}

The Stop Signal Task (SST; Logan et al., 1997) as a measure of impulsivity, defined as a decreased ability to inhibit prepotent responses. The SST consists of go and stop trials. During the go trials, the letter $\mathrm{O}$ or the letter $\mathrm{X}$ is presented for $1000 \mathrm{~ms}$, preceded by a $500 \mathrm{~ms}$ fixation point. During go trials, participants must respond as fast as possible to the $\mathrm{X}$ and the $\mathrm{O}$ using a left and a right response key on the keyboard (e.g., press left for $\mathrm{X}$ and press right for $\mathrm{O}$; instructions were counterbalanced across participants). However, during stop trials, this learned response has to be inhibited. During stop trials an auditory stop signal is presented (through headphones), and participant are instructed not to respond when the stop signal is presented. Initially, the delay between the go signal ( $\mathrm{X}$ or $\mathrm{O}$ ) and the stop signal was set at $250 \mathrm{~ms}$. Depending on the performance of the participants, a tracking procedure adapted the go-stop delay dynamically: if participants succeeded in inhibiting their response, the go-stop delay was increased by $50 \mathrm{~ms}$, thereby making it more difficult to inhibit the next trial. If participants failed to inhibit their response, the go-stop delay was decreased by $50 \mathrm{~ms}$, thereby making it easier to inhibit the next trial. The SST was designed to enable participants to correctly inhibit $50 \%$ of the stop trials.

Participants completed two practice blocks without stop signals and one with stop signals. Afterward, they completed four test blocks of 64 trials successively. There were an equal number of Xs and Os in each block and stop signals were presented on $25 \%$ of the trials, balanced over $\mathrm{X}$ and $\mathrm{O}$ trials. The order of trials was randomized. The two variables of interest were reaction time (RT) and stop delay. The dependent variable, stop signal reaction time (SSRT), was calculated by subtracting the stop delay from RT. Higher SSRTs indicate increased impulsivity or less inhibitory control.

\subsubsection{Inhibitory control manipulation}

The manipulation task was also an SST that was adapted based on the research by Verbruggen and Logan (2008) who 
demonstrated that the consistent mapping of stimuli onto stop signals increases the ability to inhibit responses to those stimuli. In this task, participants had to respond as fast as possible to foodrelated pictures (pictures of chips, nuts, and M\&Ms) and filler stimuli (pictures of chairs) by pressing a left and a right response key on the keyboard (e.g., press left for food-related pictures and press right for pictures of chairs; instructions were counterbalanced across participants). However, participants had to withhold (i.e., inhibit) responding when an auditory stop signal was presented through headphones ( $25 \%$ of the trials). The stop signal was presented after a variable stop signal delay: $100,200,300$, or $400 \mathrm{~ms}$ after the onset of the go stimulus. The task consisted of 6 blocks of 48 trials. During each block, 24 trials presented foodrelated pictures and 24 trials presented a filler stimulus. All pictures were presented twice during each block.

Importantly, there were three within-subjects conditions: One type of food (chips, nuts or M\&Ms) was always paired with a stop signal and thus responses to this type of food had to be consistently inhibited (inhibition manipulation; 8 trials), one type of food was never accompanied by a stop signal so that participants would react more impulsively toward this food product (impulsivity manipulation; 8 trials), and the third type of food was presented with a stop signal during half the trials to control for mere exposure effects without inducing impulsivity or inhibition toward this type of food (control condition; 8 trials). The assignment of the three food products to the inhibition manipulation, the impulsivity manipulation or control was counterbalanced across participants. Filler stimuli were never paired with a stop signal (24 trials), to achieve an overall proportion of $25 \%$ stop signal trials.

\subsubsection{Taste test}

In a bogus taste test, consumption was measured of the three types of food that were used in the manipulation. During the taste test, participants were asked to taste and rate the three types of food that were placed in front of them in large bowls: Paprika flavored chips ( $\pm 150 \mathrm{~g})$, BBQ-paprika flavored peanuts ( $\pm 250 \mathrm{~g})$, and M\&M's ( $\pm 250 \mathrm{~g})$. Participants were instructed to consume as much or as little as they wished to judge the taste of the food products. The experimenter then left the test room during the taste test and returned after $10 \mathrm{~min}$ and removed the bowls of food. Importantly, the primary interest was not how participants rated the types of food, but rather how much they consumed of each type of food. Without the participants' knowledge, the experimenter weighed the bowls of food before and after the taste test measured outside the test room. Energy intake was calculated for each food product by multiplying weight consumed of each food product by its caloric density.

\subsection{Procedure}

Participants were deprived of food for $2 \mathrm{~h}$ before the start of the study. All participants were invited to the lab between $11 \mathrm{am}$ and 2pm. After giving consent, participants performed the SST, which was followed by the manipulation. Next, participants performed the taste test. Finally, weight and length were measured to calculate BMI, and participants were probed for awareness of the purpose of the study and the manipulation with open questions. At the end of the study, all participants were thanked for their cooperation and received course credits or a gift certificate as remuneration for their participation.

\section{Results}

The dependent variable was the amount of calories consumed of each type of food. Food intake during the taste test was analyzed using ANCOVA with the manipulation (inhibition, impulsivity, or control) as a within-subjects factor. Baseline inhibitory control as measured with the SST was entered as a covariate in the model to examine whether initial inhibition ability influenced the effectiveness of the manipulation. At baseline, participants were on average able to successfully inhibit their responses on $36 \%$ of the stop trials (mean RT: $406.23 \pm 56.98$ ms; mean SSRT: $201.67 \pm 31.01 \mathrm{~ms})$. SSRT was entered as a continuous predictor instead of performing a median split to minimize loss of power (van Breukelen \& van Dijk, 2007). Means for high and low baseline inhibitory control abilities are estimated at $-1 S D$ and $+1 S D$, respectively.

Neither the main of effect of the manipulation, $F(2,26)=2.19$, $p=.13, \eta_{p}^{2}=.14$, nor the main effect of inhibitory control ability were significant, $F(1,27)=1.17, p=.29, \eta_{p}{ }^{2}=.04$. However, the interaction between the manipulation and inhibitory control ability was significant, $F(2,26)=4.92, p=.02, \eta_{p}^{2}=.27$. Follow-up planned contrasts revealed a significant interaction between baseline inhibitory control and the manipulation when comparing the inhibition manipulation to control, $F(1,27)=9.62, p=.004$, $\eta_{p}{ }^{2}=.26$, and also when comparing the impulsivity manipulation to control, $F(1,27)=6.04, p=.02, \eta_{p}^{2}=.18$. To illustrate these findings, Fig. 1 shows the amount of calories consumed of the food that was consistently paired with a stop signal during the inhibition manipulation (stop food), the food that was always paired with a go response during the impulsivity manipulation (go food), and the control food for participants with high (mean SSRT - $1 S D$ ) versus low (mean SSRT $+1 S D$ ) initial inhibitory control abilities.

Fig. 1 shows that the intake of the control food was significantly higher in participants with low inhibitory control abilities compared to participants with high inhibitory control abilities, $t(27)=2.66$, $p=.01, \eta_{p}{ }^{2}=.21$, while there was no difference between participants with high versus low inhibitory control abilities with respect to intake of the go food or intake of the stop food (both $t<1$, both $\eta_{p}{ }^{2}<.03$ ).

Importantly, for participants with low inhibitory control abilities, the inhibition manipulation decreased consumption of the stop food relative to control food, $t(27)=-3.31, p=.003, \eta_{\mathrm{p}}{ }^{2}=.29$, while consumption of go food did not differ significantly from the consumption of control food or the consumption of stop food (both $t<1.6$, both $\eta_{p}{ }^{2}<.10$ ). In contrast, for participants with high inhibitory

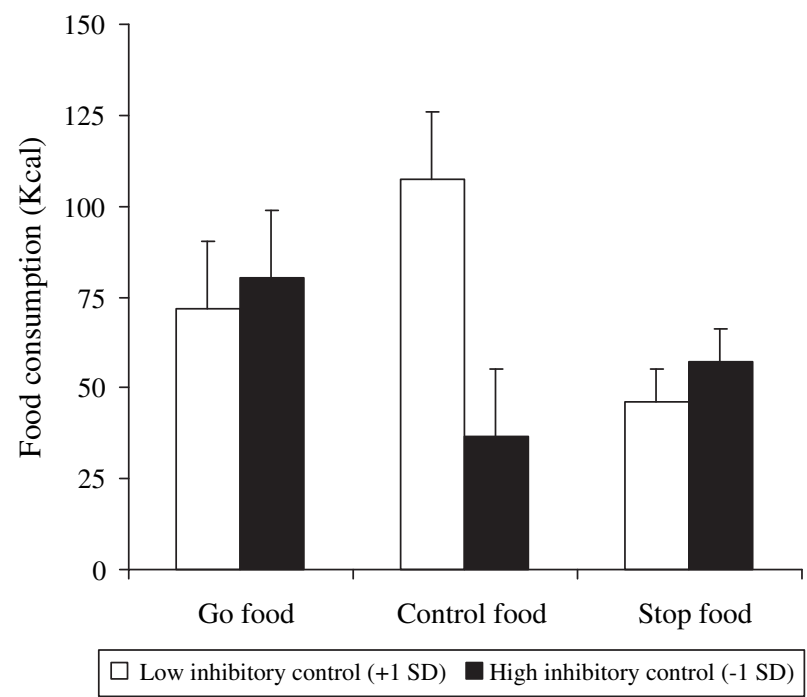

Fig. 1. Consumption (Kcal) of the food that was never paired with a stop signal (go food), the food that was paired with a stop signal on half the trials (control food), and the food that was always paired with a stop signal (stop food) in participants with low versus high initial inhibitory control abilities (respectively 1 SD above or below mean SSRT). 
control abilities, there was a trend indicating that the impulsivity manipulation increased consumption of the go food relative to control food, $t(27)=1.93, p=.06, \eta_{p}{ }^{2}=.12$, while consumption of the stop food did not differ from consumption of the control food or consumption of the go food (both $t<1.6$, both $\eta_{p}{ }^{2}<.06$ ).

Together, these findings demonstrate that, while participants with strong inhibitory control abilities consumed less of the control food than participants with weaker inhibitory control abilities, the impulsivity manipulation caused an increase in food intake so that participants with strong initial inhibitory control consumed equal amounts of the go food as participants with low initial inhibitory control. Conversely, the inhibition manipulation decreased consumption in participants with weak inhibitory control so that they did not consume more of the stop food compared to participants with strong initial inhibitory control abilities.

\section{Discussion}

The present study examined whether making people more impulsive or more inhibited toward a certain food product would respectively increase or decrease consumption of that food product. Further, it was also tested whether the effect of the manipulation on food intake was dependent on baseline inhibitory control capacity. As expected, increasing inhibition toward a food product decreased consumption of that product, but only in participants with weak baseline inhibitory control. Conversely, increasing impulsivity toward a food product increased intake of that food product, but only in participants with strong inhibitory control at baseline.

The present findings are thus in line with results by Guerrieri et al. (2009), who also found decreased food intake after an inhibition manipulation than following an impulsivity manipulation. However, unlike the study by Guerrieri et al. (2009), the present study included a control condition and the present findings therefore extend these findings by showing that increasing or decreasing inhibitory control influence food intake in opposite directions: Increasing impulsivity increases food consumption while increasing inhibition decreases food intake, which further supports the causal role of inhibition in eating behavior. The present findings further also demonstrate that the effectiveness of manipulating inhibition depends on the initial level of inhibitory control: Increasing impulsivity only increased consumption in participants who were already more impulsive at baseline (i.e., weaker inhibitory control) but not in participants who were already good at inhibiting impulsive responses at the start of the experiment. In contrast, increasing inhibition toward a food product decreased consumption in high impulsive participants but not in low impulsive participants. This differential effect of the manipulation for participants with low versus high initial inhibitory control abilities could have been caused by a floor and a ceiling effect respectively. Specifically, inhibitory control ability may have been so low in participants who were already highly impulsive at the start of the experiment, that it was impossible to further increase impulsive behavior. Similarly, it may have been impossible to further enhance inhibitory control in participants who were already good at inhibiting their responses before the manipulation. Alternatively, it could also be the case that the impulsivity and inhibition manipulation were too weak to respectively further increase impulsivity in participants with low inhibitory control and increase inhibition in participants with high inhibitory control. Hence, the present findings do not exclude the possibility that inhibitory control can also be further enhanced in people who already have strong inhibition abilities, but this may require a more extensive training procedure with increased difficulty.

Importantly, there are two possible mechanisms underlying these present findings. First, repeatedly inhibiting behavior toward a food product may have created an association between the food item and the goal of stopping behavior thereby facilitating response inhibition toward that food product (Verbruggen \& Logan, 2008). Second, unlike the study by Verbruggen and Logan (2008) were responses to neutral stimuli had to be repeatedly inhibited, participants in this study were repeatedly confronted with highly rewarding food stimuli that automatically elicit a motivational approach response as well as positive effect. Consequently, repeatedly inhibiting responses toward a food product could have disrupted action preparation to obtain the food product (e.g., motivational approach tendencies; Veling \& Aarts, in press) and/or reduced the reward value of the food product (Veling \& Aarts, 2009; Veling, Holland, \& van Knippenberg, 2008). Importantly, both possibilities can explain why repeatedly stopping responses to food is effective for participants with low baseline inhibitory control. However, the first possibility suggests that all participants may experience strong impulses to indulge in high calorie, palatable food, but participants with high inhibitory control are better at inhibiting these impulses. In contrast, participants with low inhibitory control have difficulty with inhibiting their impulses, and thus benefit from a stop goal that is attached to the food object. This implies that after the inhibition training, there was still an impulse to consume high calorie food, which could be successfully inhibited. The second explanation suggest that repeatedly stopping responses to food may be most effective for participants with low baseline inhibitory control because these participants may have stronger impulses when they perceive high calorie food, and stopping thus leads to a stronger conflict between wanting to respond and having to inhibit such impulsive reactions. As a result, stronger motor inhibition is attached to the food and/or the rewarding value of the food is decreased. Thus, this explanation predicts that the training in fact reduced the impulse to consume palatable food. The present study cannot differentiate between these possible underlying mechanisms and future research will have to further examine whether repeatedly inhibiting responses to food cues increases the ability to inhibit impulses to indulge in high calorie food, and/or reduces such impulses.

In sum, the present findings indicate that increasing inhibition is an effective method to decrease consumption of energy-dense food. The implication is that such inhibition training may be a valuable strategy in both the prevention and treatment of obesity. Obesity is a growing problem over almost the entire world and much effort is invested nowadays in both prevention and treatment. Importantly, the present findings show that strengthening inhibitory control is especially effective in people who already have difficulty controlling their food intake and therefore have a high risk of developing overweight or obesity. In this respect, it would be interesting for future research to examine the value of strengthening inhibitory control in other groups that are at risk for developing overweight such as restrained eaters. Specifically, restrained eaters chronically try to restrict their food intake, but are mostly unsuccessful in their dieting attempts (Heatherton, Herman, Polivy, King, \& McGree, 1988; Herman \& Polivy, 1980) and more prone to overeating than unrestrained eaters (Fedoroff, Polivy, \& Herman, 1997; Jansen \& Van den Hout, 1991; Rogers \& Hill, 1989), especially when they are also impulsive (Jansen et al., 2009). Further, procedures that aim to strengthen inhibitory control may prove to be a useful strategy not only for the prevention of overweight but also for treatment. Results of behavioral interventions are generally disappointing as the majority of obese individuals return to or even exceed their initial weight following treatment (e.g., Jeffery et al., 2000). One possible predictor of relapse in obesity treatment is weak inhibitory control as people with weak inhibitory control are more inclined to give in to the temptation of tasty and high-caloric food. Therefore, increasing inhibitory control abilities as 
a supplement in existing behavioral interventions may prevent weight gain following treatment by increasing resilience to everyday temptations. Cognitive (behavioral) treatments of obesity typically target disinhibited thoughts and unhealthy eating patterns (e.g., Cooper et al., 2010; Werrij et al., 2009) which may at best indirectly influence inhibition ability. Therefore, directly increasing this ability should be much more efficient and may strengthen the necessary ability to cope with such thoughts following treatment, thereby preventing relapse. In this respect, it is important to note that the present sample did consist solely of normal weight female participants and therefore it is unclear whether the present findings also generalize to the general population as well as to clinical samples. Hopefully, these initial findings will stimulate future research that aims to extend and replicate these findings also in clinical samples to further investigate the potential clinical significance of inhibitory control training for reducing overweight.

Finally, it is unclear how long the present effects on inhibition and food intake persisted. Similarly, previous studies using similar training procedures also did not include a long-term follow-up of training effects (e.g., Veling et al., 2008; Verbruggen \& Logan, 2008). Possibly, long-term enhancement of inhibitory control abilities for food-related responses may only be achieved via more extensive training procedures that involve repeated practice of inhibitory control over a longer period of time and that also incorporate a more elaborate array of food cues. This issue also needs to be addressed in future research by examining long-term effects of strengthening inhibitory control on both eating behavior and weight, to further investigate its potential clinical significance. The present findings are a first step toward this goal, by demonstrating that increasing inhibitory control effectively increases one's resilience to the temptations of tasty, high calorie food products.

\section{Funding}

Funding for this study was provided by a grant from the Dutch Technology Foundation STW.

\section{Conflict of interest}

There are no conflicts of interest.

\section{References}

Appelhans, B. M. (2009). Neurobehavioral inhibition of reward-driven feeding: implications for dieting and obesity. Obesity, 17, 640-647.

Cooper, Z., Doll, H. A., Hawker, D. M., Byrne, S., Bonner, G., Eeley, E., et al. (2010). Testing a new cognitive behavioural treatment for obesity: a randomized controlled trial with three-year follow-up. Behaviour Research and Therapy, 48, 706-713.

Dawe, S., \& Loxton, N. J. (2004). The role of impulsivity in the development of substance use and eating disorders. Neuroscience and Biobehavioral Reviews, 28, 343-351.

Fedoroff, I. C., Polivy, J., \& Herman, C. P. (1997). The effect of pre-exposure to food cues on the eating behaviour of restrained and unrestrained eaters. Appetite, 28, 33-47.

Flegal, K. M. (2005). Epidemiologic aspects of overweight and obesity in the United States. Physiology \& Behavior, 86, 599-602.

Friese, M., Hofmann, W., \& Wänke, M. (2008). When impulses take over: moderated predictive validity of explicit and implicit attitude measures in predicting food choice and consumption behaviour. British Journal of Social Psychology, 47, 397-419.

Guerrieri, R., Nederkoorn, C., \& Jansen, A. (2008). The interaction between impulsivity and a varied food environment: its influence on food intake and overweight. International Journal of Obesity, 32, 708-714.
Guerrieri, R., Nederkoorn, C., Schrooten, M., Martijn, C., \& Jansen, A. (2009). Inducing impulsivity leads high and low restrained eaters into overeating whereas current dieters stick to their diet. Appetite, 53, 93-100.

Guerrieri, R., Nederkoorn, C., Stankiewicz, K., Alberts, H., Geschwind, N., Martijn, C. et al. (2007). The influence of trait and induced state impulsivity on food intake in normal-weight healthy women. Appetite, 49, 66-73.

Heatherton, T. F., Herman, C. P., Polivy, J. P., King, G. A., \& McGree, S. T. (1988). The (mis)measurement of restraint: an analysis of conceptual and psychometric issues. Journal of Abnormal Psychology, 97, 19-28.

Herman, C. P., \& Polivy, J. P. (1980). Restrained eating. In A. J. Stunkard (Ed.), Obesity (pp. 208-225). Philadelphia: Saunders.

Hofmann, W., \& Friese, M. (2008). Impulses got the better of me: alcohol moderates the influence of implicit attitudes toward food cues on eating behavior. Journal of Abnormal Psychology, 117, 420-427.

Hofmann, W., Friese, M., \& Roefs, A. (2009). Three ways to resist temptation: the independent contributions of executive attention, inhibitory control and affect regulation to the impulse control of eating behavior. Journal of Experimental Social Psychology, 45, 431-435.

Hofmann, W., Rauch, W., \& Gawronski, B. (2007). And deplete us not into temptation: automatic attitudes, dietary restraint, and self-regulatory resources as determinants of eating behavior. Journal of Experimental Social Psychology, 43, 497-504.

Jansen, A., Nederkoorn, C., van Baak, L., Keirse, C., Guerrieri, R., \& Havermans, R. (2009). High-restrained eaters only overeat when they are also impulsive. Behaviour Research and Therapy, 47, 105-110.

Jansen, A., \& Van den Hout, M. (1991). On being led into temptation: 'Counterregulation' of dieters after smelling a 'preload'. Addictive Behaviors, 5, 247-253.

Jeffery, R. W., Epstein, L. H., Wilson, G. T., Drewnowski, A., Stunkard, A. J., \& Wing, R. R. (2000). Long-term maintenance of weight loss: current status. Health Psychology, 19, 5-16.

Logan, G. D., \& Cowan, W. B. (1984). On the ability to inhibit thought and action: a theory of an act of control. Psychological Review, 91, 295-327.

Logan, G. D., Schachar, R. J., \& Tannock, R. (1997). Impulsivity and inhibitory control. Psychological Science, 8, 60-64.

Miyake, A., Friedman, N. P., Emerson, M. J., Witzki, A. H., \& Howerter, A. (2000) The unity and diversity of executive functions and their contributions to complex "frontal lobe" tasks: a latent variable analysis. Cognitive Psychology, $41,49-100$.

Nederkoorn, C., Braet, C., Van Eijs, Y., Tanghe, A., \& Jansen, A. (2006). Why obese children cannot resist food: the role of impulsivity. Eating Behaviors, 7, 315-322.

Nederkoorn, C. Guerrieri, R. Havermans, R. C. Roefs, A. \& Jansen, A. (2009). The interactive effect of hunger and impulsivity on food intake and purchase in a virtual supermarket. International Journal of Obesity and Related Metabolic Disorders, 33, 905-912.

Nederkoorn, C., Houben, K., Hofmann,, W., Roefs, A., \& Jansen, A. (2010). Control yourself or just eat what you like? Weight gain over a year is predicted by an interactive effect of response inhibition and implicit preference for snack foods. Health Psychology, 29, 389-393.

Nederkoorn, C., Jansen, E., Mulkens, S., \& Jansen, A. (2007). Impulsivity predicts treatment outcome in obese children. Behaviour Research and Therapy, 45 1071-1075.

Rogers, P. J., \& Hill, A. J. (1989). Breakdown of dietary restraint following mere exposure to food stimuli: interrelationship between restraint, hunger, salivation, and food intake. Addictive Behaviors, 14, 387-397.

Strack, F., \& Deutsch, R. (2004). Reflective and impulsive determinants of social behavior. Personality and Social Psychology Review, 8, 220-247.

van Breukelen, G. J. P., \& van Dijk, K. R. A. (2007). Use of covariates in randomized controlled trials. Journal of the International Neuropsychological Society, 13, 903-904.

Veling, H., \& Aarts, H. (2009). Putting behavior on hold decreases reward value of need-instrumental objects outside of awareness. Journal of Experimental Social Psychology, 45, 1020-1023.

Veling, H., \& Aarts, H. Unintentional preparation of motor impulse after incidental perception of need-rewarding objects. Cognition and Emotion, in press.

Veling, H., Holland, R. W., \& van Knippenberg, A. (2008). When approach motivation and behavioral inhibition collide: behavior regulation through stimulus devaluation. Journal of Experimental Social Psychology, 44, 1013-1019.

Verbruggen, F., \& Logan, G. D. (2008). Automatic and controlled response inhibition: associative learning in the go/no-go and stop-signal paradigms. Journal of Experimental Psychology: General, 137, 649-672.

Wang, Y., \& Beydoun, M. A. (2007). The obesity epidemic in the united statesgender, age, socieconomic, racial/ethnic, and geographic characteristics: a systematic review and meta-analysis. Epidemiologic Reviews, 29, 6-23.

Werrij, M. Q., Jansen, A., Mulkens, S., Elgersma, H., Ament, A., \& Hospers, H. J. (2009). Adding cognitive therapy to dietetic treatment prevents relapse in obesity Journal of Psychosomatic Research, 67, 315-324. 